\title{
Development and implementation of a minimum theoretical-practical program to standardize the training of Brazilian foot and ankle surgeons
}

\author{
Desenvolvimento e efetivação de um programa mínimo de treinamento \\ teórico-prático para uniformizar a formação de médicos brasileiros \\ especialistas em pé e tornozelo
}

\author{
Ricardo Cardenuto Ferreira', Marco Túlio Costa ${ }^{1}$ \\ 1. Santa Casa de Misericórdia de São Paulo, São Paulo, SP, Brazil.
}

\begin{abstract}
Objective: 1) to identify characteristics of the functioning and production of training centers responsible for the training of foot and ankle specialists in Brazil; 2) establish minimum quality criteria to provide adequate professional training of the foot and ankle specialist; 3) create a baseline to endorse the minimum foot and ankle specialist training program; 4) to rank, in terms of qualification and efficiency, the training centers of specialists in the area of foot and ankle.

Methods: Protocol containing information provided by physicians responsible for 31 accredited national services as centers for training foot and ankle specialists at ABTPé in the 2012-2015 quadrennium. Results: minimum operating and production criteria were established based on the information collected. We identified that: 1) it was possible to establish criteria for a possible standardization in the training programs, both in the theoretical and practical field; 2 ) the relevant scientific output of the training centers is still low and should be stimulated to increase both quantity and quality; 3 ) the academic qualification of physicians responsible for training specialists is low; 4) The classification of training centers according to hierarchical quality criteria can be established by objective criteria.

Conclusion: Quality goals, with objective and well-defined criteria, could be established allowing standardizing the type of training offered to training specialists distributed throughout the national territory, making it more uniform. The evaluation criteria adopted also allowed to establish a hierarchical classification of training centers in the area of foot and ankle, creating a reference base to qualify the training offered in these institutions.
\end{abstract}

Keywords: Education, medical, continuing; Inservice training; Orthopedic Surgeons/education; Foot; Ankle.

\section{RESUMO}

Objetivo: 1) identificar características do funcionamento e produção dos centros de treinamento responsáveis pela formação dos médicos especialistas em pé e tornozelo no Brasil; 2) estabelecer critérios mínimos de qualidade para oferecer formação profissional adequada ao especialista na área do pé e tornozelo; 3) criar base de referência para referendar o programa mínimo de treinamento do especialista em pé e tornozelo; 4) hierarquizar, em termos de qualificação e eficiência, os centros de formação de especialistas na área de pé e tornozelo.

Métodos: Protocolo contendo informações fornecidas pelos médicos responsáveis pelos 31 serviços nacionais credenciados como centros formadores de especialistas em pé e tornozelo junto à ABTPé no quadriênio 2012-2015.

Resultados: Foram estabelecidos critérios mínimos de funcionamento e produção com base nas informações coletadas. Identificamos que: 1) foi possível estabelecer critérios para uma possível padronização nos programas de treinamento, tanto no campo teórico quanto prático; 2) a produção científica relevante dos centros formadores ainda é baixa e deve ser estimulada para aumentar tanto em quantidade quanto qualidade;

Study performed at the Associação Brasileira de Medicina e Cirurgia do Tornozelo e Pé, São Paulo, SP, Brazil.

Correspondence: Ricardo Cardenuto Ferreira. Rua: Dr. Cesário Mota Júnior, 112, Vila Buarque, São Paulo, SP, Brasil, CEP: $01221-010$

Conflicts of interest: none. Source of funding: none.

Date received: December 20, 2019. Date accepted: December 20, 2019. Online: December 12, 2019.

\section{(c) (1)}

Copyright $\odot 2019$ SciJFootAnkle 
3) a qualificação acadêmica dos médicos responsáveis pelo treinamento de especialistas é baixa; 4) a classificação dos centros de treinamento, segundo critérios hierárquicos de qualidade, pode ser estabelecida por meio de critérios objetivos.

Conclusão: Puderam ser estabelecidas metas de qualidade com critérios objetivos e bem definidos, permitindo padronizar o tipo de treinamento oferecido aos especialistas em formação distribuídos pelo território nacional, tornando-o mais uniforme. Os critérios de avaliação adotados permitiram também estabelecer uma classificação hierárquica dos centros de formação na área de pé e tornozelo, criando uma base de referência para qualificar o treinamento oferecido nessas instituições.

Palavras-chave: Educação médica continuada; Capacitação em serviço; Cirurgiões ortopédicos/educação; Pé; Tornozelo.

How to cite this article: Ferreira RC, Costa MT. Development and implementation of a minimum theoretical-practical program to standardize the training of Brazilian foot and ankle surgeons. Sci J Foot Ankle. 2019;13(4): 239-50.

\section{INTRODUCTION}

As knowledge in the medical field is undergoing a rapid acceleration in recent decades, the specialization of orthopedists in different areas is today an unquestionable reality. However, the specific training of future surgeons has not been established yet, nor defined through objective and practical parameters. Since 2007, the Brazilian Society of Medicine and Surgery of the Ankle and Foot (ABTPé) has officially assumed the role of regulating and monitoring the training of orthopedists who wish to focus their practice in the foot and ankle area ${ }^{(1)}$. During the implementation of such action, ABTPé's Education and Training Board identified the need to establish some guidelines capable of answering two vital questions: what is type of training required to prepare future foot and ankle surgeons properly? How could this training be extended in the most uniform way possible so as to allow a minimum standard for all cities and states in the in Brazil country?

In 2013, a pilot study was published in the ABTPé journal(1) containing information provided by the 31 training centers officially registered with ABTPé as foot and ankle training centers. Such pilot study data were based on the year of 2012 and contained information on the activities performed at the training centers, highlighting: 1) practical medical activities, like outpatient care and surgeries; 2 ) theoretical activities related to the type of education offered; 3 ) the academic qualification of the service clinical staff and the institution's scientific production; and 4) the organizational structure of the training center. Based on this study, some reference parameters for the creation of a minimum national training program for foot and ankle surgeons were proposed. However, as the database referred only to the year preceding the study, it was identified a need to expand the amount of data to allow more comprehensive conclusions. Thus, the present study uses the same reference standards initially proposed to assess the quality of the training offered by the foot and ankle trai- ning centers officially registered with ABTPé. This study compiles data from 2012 to 2015.

The purpose of this study is to effectively consolidate the parameters proposed as a primary reference to introduce a minimum national training program for orthopedists who wish to specialize in the treatment of foot and ankle disorders.

\section{METHODS}

In 2012, ABTPé's Education and Training Board previously prepared a form containing specific questions that was sent by email to the heads of all 31 services registered with ABTPé as foot and ankle training centers, which are distributed as follows: 13 centers in São Paulo (Pavilhão Fernandinho Simonsen da Santa Casa de Misericórdia, Hospital das Clínicas da Universidade de São Paulo, Hospital São Paulo - UNIFESP, Hospital do Servidor Público Estadual, Hospital da Associação Beneficente Nossa Senhora do Pari, Complexo Hospitalar do Mandaqui, Hospital Santa Marcelina, Hospital da Faculdade de Medicina do ABC, Hospital IFOR, Hospital de Base de São José do Rio Preto, Hospital Universitário de Taubaté, Hospital da PUC Campinas, and Hospital da Universidade Estadual de Campinas); four centers in Minas Gerais (HC Ortopédico da Universidade Federal de Uberlândia, Hospital Madre Teresa, Hospital Governador Israel Pinheiro, and Hospital Mater Dei); three centers in Paraná (Hospital das Clínicas da Universidade Federal do Paraná, Hospital Cajurú, and Hospital Evangélico); four centers in Rio de Janeiro (Hospital da Santa Casa de Misericórdia, Instituto Nacional de Trauma Ortopédico - INTO, Hospital Municipal Lourenço Jorge, and Hospital Clementino Fraga); two centers in Santa Catarina (Hospital Regional Miranda Gomes and Instituto de Ortopedia de Santa Catarina); two centers in Bahia (Hospital Martagão, and Hospital Santa Izabel); two centers in Goiás (Hospital da Universidade Federal de Goiás and Instituto Ortopédico 
de Goiânia); and a center in Rio Grande do Sul (Instituto de Ortopedia de Passo Fundo). In the previous pilot study published in 2013, 31 training centers were also evaluated, however, two changes occurred in the subsequent years that compose this new study period: 1) Hospital Novo Mundo, in the state of Paraná, was de-accredited and completely excluded from the study; and 2) Hospital Clementino Fraga, in the state of Rio de Janeiro, was accredited and included in the study as of 2013.

The survey form requested the following information regarding the 2012-2013-2014-2015 quadrennium: 1) number of physician trainees receiving training in the institution; 2) academic qualification of the staff; 3) quantity and quality of national and international scientific publications by the service; 4) annual number of patients seen at the outpatient foot and ankle clinic; 5) annual number of surgeries exclusively performed in the foot and ankle area; 6) type and complexity of surgeries performed throughout the year (high, medium, or low complexity); 7) content of scientific activities offered to the physicians in training, such as specific seminars and theoretical classes, as well as the number of meetings held to discuss complex clinical cases; and 8) other relevant information regarding the practical operation of the service, such as the organization and documentation of treated patients.

To assess the quality and performance of accredited services that operate as training centers for foot and ankle surgeons, some criteria were considered essential. These criteria were based on the previous experience acquired during activities that involved teaching, training, and continuing education in traditional institutions that composed the Board Directors of ABTPé at the time of the form elaboration. This was made empirically, since there is a significant lack of prior information on this topic, especially involving the foot and ankle area, in any type of publication available both nationally and internationally.

The criteria adopted involved the number of patients seen and the capacity of each service (number of outpatient consultations, number and type of surgeries), academic criteria (clinical staff qualification and scientific production), and theoretical teaching curriculum criteria (classes, seminars, clinical meetings, and case discussions). All information gathered and tabulated to be analyzed in this study was provided and is the sole responsibility of the head of each of the 31 services officially accredited as training centers by ABTPé (see reference source).

The form requested information regarding the number of classes and seminars given, including the topic discussed and the number of clinical meetings and discussions held on complex cases related to foot and ankle disorders, requesting their dates and the names of the coordinators responsible for conducting such meetings. It also contained a list to be filled out with information related to surgical cases specifying: 1 ) the date of surgery; 2 ) the operated side; 3 ) the diagnosis; 4 ) the type of surgery performed; 5) the name of the surgeon responsible for conducting the case, and 6) the trainee's position during the surgery (surgeon, first or second assistant).

The head of each accredited service submitted the completed form by email. Then, all data were compiled, tabulated, and stored in an EXCEL spreadsheet for subsequent analysis.

\section{Assessment Scale}

A scale specially developed to qualitatively assess the education and training programs offered by the accredited centers was empirically employed. The scale score ranges from 0 to 10 and the following concepts were adopted: a) excellent - score from 9.0 to $10 ;$ b) good - score ranging from 6.0 to 8.9 (from 6.0 to 7.9 - minus value; from 8.0 to 8.9 - plus value); c) sufficient - score ranging from 4.0 to 5.9 (from 4.0 to 4.9 - minus value; from 5.0 to 5.9 - plus value); d) poor-score ranging from 2.0 to 3.9 (from 2.0 to 2.9 - minus value; from 3.0 to 3.9 - plus value); e) insufficient: score below 2.0 (from zero to 0.9 - minus value; from 1.0 to 1.9 - plus value).

Based on the score values obtained, the insufficient concept (below 3.0 points) was defined as the minimum cutoff criterion. It means that any service classified in this level would be offering a low quality, insufficient training for foot and ankle surgeons according to the minimum standards required. In situations like these, our recommendation would be the immediate de-accreditation of the service as an official training center by ABTPé.

\section{Score Scale}

The score scale ranges from 0 to 10 and includes the assessment of seven main items: 1) minimum number of outpatient visits of patients exclusively presenting with foot and ankle disorders - weight 2; 2) minimum number of surgeries in patients with conditions exclusively involving the foot and ankle area - weight 2;3) surgeries complexity degree (minor, medium, and major surgeries) - weight 1;4) clinical staff academic qualification (PhD, master's degree, graduate degree in progress) - weight 1 ; 5) clinical staff scientific production (national and international publications) - weight 2 ; 6) minimum theoretical program con- 
tent (classes, seminars, clinical meetings, case discussions) - weight 1 ; 7) organization and documentation of patients treated at the institution and number of physicians trained by the institution in the last five years - weight 1.

\section{Awarding Points:}

- Item 1: minimum number of outpatient consultations (score: $\mathbf{0}$ when the minimum target set was not met; score: 1 when at least $2 / 3$ of the minimum target set was met; score: $\mathbf{2}$ when the minimum target set was met).

- Item 2: minimum number of surgeries (score: $\mathbf{0}$ when the minimum target set was not met; score: 1 when the minimum target set was met, but the minimum quota was less than 15 of the 20 items stipulated as essential surgeries - see Table 1; score: $\mathbf{2}$ when the minimum target set was met and the minimum quota of at least 15 of the 20 items stipulated as essential surgeries was also reached - see Table 1).

- Item 3: surgeries complexity degree (score: $\mathbf{0}$ when $50 \%$ or more of the procedures performed were of low complexity - Size III, which includes the treatment of congenital clubfoot in the newborn, minor amputation, correction of toe deformities, and removal of implant material, or when less than $70 \%$ of the procedures performed were of medium complexity - Size II, which includes fractures, arthroscopy, forefoot osteotomies, ligament or tendon reconstruction, tumor resection, hallux valgus or rigid hallux correction, congenital malformation, and major amputation; score $\mathbf{0 . 5}$ when 70\% or more of the procedures performed were of medium complexity; score 1 when $20 \%$ or more of the procedures performed were of high complexity, as long as this number exceeds 50 surgeries/year - Size I, which includes post-traumatic reconstruction, midfoot or hindfoot arthrodesis, treatment with circular external fixator, and midfoot or hindfoot osteotomies).

- Item 4: clinical staff academic qualification (score: $\mathbf{0}$ when no one in the clinical staff has an academic qualification; score: $\mathbf{0 . 5}$ when there is at least one master in the clinical staff; score: 1 when there is at least one PhD in the clinical staff).

- Item 5: clinical staff scientific production (the scores are added according to the value accumulated for the different levels of publication, reaching a maximum score of two points) (score 0.8: international A

Table 1. Distribution of the 315 operated extremities, corresponding to the corrected annual mean values* of the 31 training centers, according to the 20 specific types of surgical treatment, The procedures were classified according to surgical size and, regardless of the number of surgical procedures performed simultaneously, we computed only the major size for each operated extremity

\begin{tabular}{|c|c|c|}
\hline Major Procedures (I) & Medium Procedures (II) & Minor Procedures (III) \\
\hline $\begin{array}{l}\text { Mediotarsal osteotomy } \\
\text { 12/year }\end{array}$ & $\begin{array}{c}\text { Acute fractures } \\
91 / \text { year }\end{array}$ & $\begin{array}{c}\text { Removal of synthesis material } \\
\text { 36/year }\end{array}$ \\
\hline $\begin{array}{l}\text { Triple arthrodesis } \\
\text { 10/year }\end{array}$ & $\begin{array}{l}\text { Hallux valgus } \\
\text { 38/year }\end{array}$ & $\begin{array}{c}\text { Smaller fingers } \\
15 / \text { year }\end{array}$ \\
\hline $\begin{array}{l}\text { Post-traumatic reconstruction } \\
\text { 8/year }\end{array}$ & $\begin{array}{c}\text { Tendon injuries } \\
\text { 30/year }\end{array}$ & $\begin{array}{c}\text { Minor amputation } \\
\text { 5/year }\end{array}$ \\
\hline $\begin{array}{l}\text { Ankle arthrodesis } \\
\text { 7/year }\end{array}$ & $\begin{array}{c}\text { Ankle arthroscopy } \\
\text { 10/year }\end{array}$ & $\begin{array}{c}\text { Congenital clubfoot in the newborn } \\
4 / \text { year }\end{array}$ \\
\hline $\begin{array}{l}\text { Midfoot arthrodesis } \\
6 / \text { year }\end{array}$ & $\begin{array}{c}\text { Foot or Ankle tumor } \\
\text { 10/year }\end{array}$ & \\
\hline \multirow[t]{5}{*}{$\begin{array}{l}\text { Circular external fixator } \\
\text { 3/year }\end{array}$} & $\begin{array}{c}\text { Metatarsal osteotomy } \\
\text { 9/year }\end{array}$ & \\
\hline & $\begin{array}{l}\text { Ankle ligament injuries } \\
7 / \text { year }\end{array}$ & \\
\hline & $\begin{array}{l}\text { Rigid hallux } \\
\text { 6/year }\end{array}$ & \\
\hline & $\begin{array}{l}\text { Foot malformations } \\
5 / \text { year }\end{array}$ & \\
\hline & $\begin{array}{c}\text { Major amputation } \\
\text { 3/year }\end{array}$ & \\
\hline Total: 60/year (19\%) & Total: 209/year (66\%) & Total: 46/year (15\%) \\
\hline
\end{tabular}

* The corrected annual mean values was excluded from the mean calculation the three highest and lowest values from the annual number of surgeries performed by each of the 31 training centers. 
level publication - Journal Bone Joint Surgery, Clinical Orthopaedics, Foot and Ankle International, Foot and Ankle Orhopaedics + score 0.6: international B level publication - other international journals + score 0.4: national A level publication - Revista Brasileira de Ortopedia, Acta Ortopédica, Revista ABTPé (currently, Scientific Journal of Foot and Ankle) + score 0.2: national B level publication - other national journals).

- Item 6: didactic activities encompassing clinical meetings to discuss cases involving the foot and ankle (score: $\mathbf{0}$ when the minimum target set was not met; score: $\mathbf{0 . 5}$ when the minimum target set was met); didactic activities encompassing seminars and theoretical classes with essential foot and ankle topics (score: $\mathbf{0}$ when the minimum target was not met; score: $\mathbf{0 . 5}$ when the minimum target set was met).

- Item 7: organization and documentation of patients treated at the institution and number of physicians trained by the institution in the last nine years (score: $\mathbf{0}$ when there is no adequate organization and documentation or when the institution did not give trainings in the 2012-2015 period; score: $\mathbf{0 . 5}$ when the institution maintains an adequate organization and documentation and trained at least one trainee in the 2012-2015 period; score: 1 when it maintains an adequate organization and documentation and trained at least four trainees in the 2012-2015 period).

Items 1, 2, and 3 address the service's productive capacity in the care and treatment of patients, characterizing the degree to which physicians are exposed to foot and ankle disorders during their practical training. These three items are considered important, and we assign them 50\% of the possible points on the scale.

Items 4 and 5 address the academic aspects of the service, characterizing the staff's qualification and scientific production. Altogether, they sum up $30 \%$ of the possible points on the scale.

Finally, items 6 and 7 address the didactic activities offered to the physicians in training, the organization of services, and their ability to train surgeons. Altogether, they sum up $20 \%$ of the possible points on the scale.

In the methodology adopted to analyze the information provided by the 31 registered services, only the mean values for each item surveyed were considered. In order to try to correct any discrepancies arising from the sample heterogeneity (larger versus smaller center services), the criterion adopted for the mean calculation was the exclusion of extreme values for each of the items surveyed. Thus, the three highest and the three lowest values were excluded from the final mean calculation. The final value obtained was called the corrected annual mean.

For the hierarchical classification of services, the performance in the items below was used as a tiebreaking criterion for the final score, in order of increasing priority: 1) corrected mean number of outpatient consultations in the period; 2) corrected mean number of surgeries in the period; 3 ) complexity of surgeries performed in the period; 4) clinical staff academic qualification; 5) scientific production in the period; 6) theoretical program in the period; 7) documentation organization in the period.

\section{RESULTS}

The study final result was subdivided into eight topics and showed the following:

\section{1) Number of outpatient consultations in the foot and ankle area:}

Among the 31 assessed services, the corrected overall annual mean for the number of outpatient consultations throughout each year during the 2012-2015 quadrennium was 4,000 consultations (range from 850 to 14,900). It corresponds to an average of approximately 330 consultations per month, or 82 consultations per week. Taking into account regional differences and the variable population sizes, as well as the size of the different hospitals structures, it was decided to arbitrarily reduce such number to 3,500 annual consultations and to define this corrected annual mean as the minimum number of outpatient consultations that a service that proposes to train foot and ankle surgeons should perform. This is equivalent to 292 outpatient consultations per month, or 73 consultations per week. Considering such discount of approximately $12 \%$ in the mean number of annual outpatient consultations, 15 of the 31 services accredited as training centers met the minimum level of 3,500 consultations/year, corresponding to $48 \%$ of the total services, and scored the maximum of two points in this criterion; five met at least $2 / 3$ of the established level, corresponding to $16 \%$ of the total services, and scored one; while 11 services, totaling $36 \%$ of the total services, did not meet the minimum level and, consequently, scored zero in this criterion.

\section{2) Number of foot and ankle surgeries:}

Among the 31 services evaluated, the corrected overall annual mean for the number of surgeries during the 2012-2015 quadrennium was 340 (range from 158 to 656). 
It corresponds to an average of 28 surgeries per month. Taking into account the regional differences and the variable population sizes, as well as the size of the different hospital structures, 315 annual surgeries was defined as the minimum number of surgeries that a service that proposes to train foot and ankle surgeons should perform. This value was considered because it corresponds to $9 \%$ of the annual number of consultations adopted as the minimum level for outpatient care and because it is very close to the corrected annual mean proportion between the number of consultations and the number of surgeries performed annually by the 31 services in the studied period, which was originally $9 \%$ (range from 4 to 31 ). This is equivalent to 23 surgeries per month or approximately six surgeries per week. Considering this approximate discount of $7 \%$ in the annual mean number of surgeries, 12 of the 31 accredited services did not meet the level of 315 surgeries/year in the quadrennium, totaling $39 \%$; consequently, they scored zero. Among the 19 services that met the target of 315 surgeries/year, only six managed to meet the minimum number of surgeries/year performing at least 15 of the 20 essential procedures stipulated; consequently, they obtained the maximum score of two points. Despite meeting the minimum number of 315 surgeries/year, the remaining 13 services failed to meet the target of performing the minimum number of 15 of 20 essential surgical procedures and scored one.

Regarding the variety of 20 surgical procedures considered essential for the proper training of foot and ankle surgeons, Table 1 shows the corrected annual mean values performed by the 31 services in the studied quadrennium. We emphasize that these data constitute a reference base hitherto nonexistent and, thus, they can become part of the minimum surgical volume exposure recommended for foot and ankle surgeons throughout their training year.

\section{3) Variety and complexity of foot and ankle surgeries:}

Among the 31 services surveyed, the corrected annual surgery distribution mean according to the complexity degree was as follows: size I - major, high complexity surgeries: $15 \%$ of total surgeries performed; size II - medium, moderate complexity surgeries: $66 \%$ of surgeries performed; and size III - minor, low complexity surgeries: $19 \%$ of surgeries performed.

Among the 31 services assessed, eight (26\%) performed surgeries classified as being of high complexity (size I: post-traumatic reconstruction, hindfoot and midfoot arthrodesis, treatment with circular external fixator, midfoot or hindfoot osteotomies) in at least $20 \%$ of operated cases, scoring one. Other eight services (26\%) performed surgeries classified as being of medium complexity (size II: fractures, arthroscopy, forefoot osteotomies, ligament or tendon reconstruction, tumor resection, hallux valgus or rigid hallux correction, congenital malformation, major amputation) in at least $70 \%$ of operated cases, scoring 0.5 . The remaining 15 services did not score in this item because they did not meet the minimum percentage of $70 \%$ of medium-complexity surgeries (size II). None of the services performed minor surgery in more than $50 \%$ of operated cases.

The corrected annual mean number for each of the 20 specific types of surgical treatment considered essential performed by the 31 surveyed services was as follows: post-traumatic reconstruction (8) (range from 3 to 17); ankle arthrodesis (7) (range from 4 to 15); triple arthrodesis (10) (range from 4 to 27); midfoot arthrodesis (6) (range from 2 to 11); circular external fixator (3) (range from 1 to 13); mediotarsal osteotomy (12) (range from 4 to 28); metatarsal osteotomy (9) (range from 2 to 22); acute fractures (91) (range from 49 to 146); ankle ligament injuries (7) (range from 2 to 14); tendon injuries (30) (range from 13 to 60); hallux valgus (38) (range from 19 to 67); rigid hallux (6) (range from 3 to 11); tumor (10) (range from 4 to 20); ankle arthroscopy (10) (range from 1 to 21); foot malformations (5) (range from 0 to 13); major amputation (3) (range from 0 to 7); minor amputation (5) (range from 2 to 14); smaller fingers (15) (range from 5 to 30); congenital clubfoot in the newborn (10) (range from 0 to 76); removal of synthesis material and other minor procedures (36) (range from 13 to 66). These data are summarized in Table 1.

In this study, it was identified that throughout the 48 months surveyed, some of the 31 services accredited as training centers did not perform a few of the 20 specific types of surgery considered essential in the training of foot and ankle surgeons. Among the essential surgical treatments not performed by some of the training centers, the following procedures stood out: congenital clubfoot in the newborn (13 services did not perform any procedure, totaling 42\%); circular external fixator for correction of feet and ankle deformities (three services did not perform any procedure, totaling 10\%); major amputation (three services did not perform any procedure, totaling 10\%); correction of foot malformations (two services did not perform any procedure, totaling 6\%); and ankle arthroscopy (a single service did not perform any procedure, totaling $3 \%$ ). 


\section{4) Clinical staff academic qualification:}

Among the 31 services, 16 (52\%) declared that they had at least one PhD in their clinical staff, scoring one. Seven services $(22 \%)$ had at least one master in their clinical staff, scoring 0.5 . Eight services (26\%) did not have any member holding an academic degree in their clinical staff, scoring zero.

\section{5) Scientific production by the service:}

In this criterion, the period was extended beyond the 2012-2015 quadrennium in order to consider publications made as of 2007 and, even so, it was identified that three services (10\%) did not publish any article, scoring zero.

The remaining 28 services (90\%) were responsible for publishing 141 articles in A level national journals: 89 articles published in Revista da ABTPé (currently, Scientific Journal of Foot and Ankle), 32 articles published in Revista Brasileira de Ortopedia, and 20 articles published in the journal Acta Ortopédica. Eighteen articles were published in other B level national journals. A total of 159 articles were published by the training centers between 2007 and 2015 in national journals, $89 \%$ of which were A level national journals.

Four services (13\%) alone were responsible for publishing 16 articles in A level international journals: 15 articles published in the journal Foot and Ankle International and only one article published in the journal Bone and Joint Surgery. Forty-five articles were published in other B level international journals. A total of 61 articles were published by the training centers between 2007 and 2015 in international journals, only $26 \%$ of them in A level international journals.

Adding up all publications made by the 28 services in the period between 2007 and 2015, the total of 220 publications was reached, 159 in national journals (72\%), and 61 in international journals (28\%); 157 of A level (71\%) and 63 of B level (29\%). Considering only the 28 services that made some type of publication between 2007 and 2015, the average is approximately eight articles published in nine years; therefore, less than one article published annually by each foot and ankle training center.

\section{6) Theoretical program content:}

Among the 31 services assessed, 38 was the corrected annual mean number of meetings held to discuss clinical cases in the foot and ankle area over the studied quadrennium. Twenty services (64\%) scored 0.5 for meeting such target mean, while 11 services (36\%) scored zero for failing to meet this minimum theoretical program.
Regarding the classes and seminars offered to physicians in training, 29 was the corrected annual mean number of the total of seminars aimed at addressing basic topics in the foot and ankle area in the studied quadrennium. Nineteen services $(61 \%)$ scored 0.5 for meeting the such target mean, while other 12 services (39\%) scored zero for failing to meet this minimum theoretical program.

The corrected annual mean number of all didactic activities carried out to cover essential topics in the foot and ankle area over the studied quadrennium, including seminars and theoretical classes, is shown in Table 2.

Some specific class and seminar topics were not addressed by some of the 31 services surveyed, among which: foot and ankle anatomy and physiology (3 services did not address it - 10\%); foot and ankle congenital diseases ( 1 service did not address it - 3\%); general foot and ankle topics (1 service did not address it $-3 \%$ ).

\section{7) Organization of documentation and statistical data related to the training program, volume of patients' care and treatment, and number of physicians trained by the institution in the last nine years (2007-2015):}

Two hundred and sixty-three foot and ankle surgeons were trained by the 31 training centers in the nine years period between 2007-2015. One hundred and forty-six (56\%) graduated from one of the 13 accredited training centers located in the state of São Paulo; 24 (9\%), in one of the four accredited training centers located in the state of Rio de Janeiro; 24 (9\%), in one of the four accredited training centers located in the state of Minas Gerais; 23 (9\%), in one of the three accredited training centers located in the state of Paraná; 17 (6\%), in one of the two accredited training centers located in the state of Goiás; 14 (5\%), in one of the two accredited training centers located in the state of Bahia; 12 $(5 \%)$, in one of the two accredited training centers located in the state of Santa Catarina; and only three (1\%) graduated from the only accredited training center located in the state of Rio Grande do Sul. In this period, three training centers located in São Paulo were responsible for the graduation of 103 new surgeons, corresponding to $39 \%$ of the total. The Instituto de Ortopedia e Traumatologia do Hospital das Clínicas da Universidade de São Paulo, graduated 45 new surgeons ( $17 \%$ of the total); Pavilhão Fernandinho Simonsen, do Departamento de Ortopedia e Traumatologia da Santa Casa de Misericórdia de São Paulo graduated 32 of them ( $12 \%$ of the total); and the Departamento de Ortopedia e Traumatologia do Hospital São Paulo da Universidade Federal de São Paulo, graduated 26 of them (10\% of the total). All 31 accredited centers trained at least one new surgeon during the period studied. 
Table 2. Distribution of the corrected annual mean value of all 29 didactic activities carried out to cover essential topics in the foot and ankle area over the studied quadrennium, including seminars and theoretical classes

\begin{tabular}{|l|c|}
\hline Theme of didactic activities & Number of didactic activities \\
\hline Anatomy and physiology & 1 (range from 0 a 2$)$ \\
\hline Traumatic diseases & 8 (range from 5 a 11) \\
\hline Degenerative diseases & 9 (range from 5 a 16$)$ \\
\hline Neurological diseases & 3 (range from 2 a 5$)$ \\
\hline Congenital diseases & 3 (range from 1 a 8$)$ \\
\hline General foot and ankle topics & 5 (range from 1 a 10$)$ \\
\hline Total & 29 (range from 20 a 48$)$ \\
\hline
\end{tabular}

Regarding the organization and documentation criteria, the accredited centers were subjectively assessed based on the consistency and accuracy in filling out the relevant forms during the period of study.

In this criterion, four services (13\%) scored zero; 18 services (58\%) scored 0.5 , and nine services (29\%) scored one.

\section{8) Final score and ranking according to the assessment scale:}

Table 3 shows the classification of the 31 services surveyed based on the score obtained. Two services (6\%) were classified as excellent; four services (13\%), as good - one plus (+) and three minus (-); 11 services (35\%), as sufficient - four plus (+) and seven minus (-); 11 services (35\%) were classified as poor - seven plus (+) and four minus (-); and three services (10\%) were classified as insufficient, two plus (+) and one minus (-).

\section{DISCUSSION}

This study was aimed to map the national profile of education and training quality in the subspecialty of foot and ankle as developed by centers accredited by ABTPé throughout the Brazilian territory. Coordinated and developed for the last eight years by the successive mandates of the Education and Training Board and Continuing Education Board of ABTPé, its main objective was to establish a standard reference to assess the quality of the content offered to physicians in training within this subspecialty. The second objective, and perhaps the most important one, was to establish a minimum national program, thus reducing possible distortions in the training to be offered to future surgeons in the field.
The single known precedent in the national literature was the pilot study published in Revista ABTPé in 2013, which served as a reference for this new, more comprehensive study. This study analyzed data obtained within the context of the annual re-registration program, which were provided by the head of each training center officially registered with ABTPé as of 2007. These data were compiled and carefully analyzed by the study authors during the years 2017 and 2018, referring to the four-year period between 2012 and 2015.

Initially, as there was no precedent in the literature, it was necessary to develop a pilot study creating criteria to assess the quality of the training offered by training centers. These criteria were defined by foot and ankle surgeons with more than 20 years of experience in teaching and training and, although some criteria adopted are subjective, we tried to keep subjectivity at a minimum by establishing well-defined scoring rules. At the same time, most of the criteria used for assessing the volume of consultations of patients with specific problems in the foot and ankle area were very objective, as well as for assessing the quantity, variety, and difficulty of the surgical procedures employed. We consider that the medical training of the foot and ankle surgeon requires an intense exposure to the most varied surgeries and diseases that are part of the daily routine of this subspecialty, including the proportional performance of surgeries to treat simple, difficult, and more complex cases, which pose a greater technical difficulty.

To establish the minimum number of outpatient consultations and surgeries that a training center should perform in order to provide adequate training conditions, we calculated the arithmetic mean of the volume of care provided by the 31 accredited services between 2012 and 2015. In order to try to correct possible distortions caused by regional differences and by the uneven structure of the services analyzed, we chose to use the correction of this simple arithmetic mean. To do so, we excluded from the mean calculation the three highest and lowest values, thus obtaining the so-called corrected arithmetic mean. By removing the extreme values from the curve, we believe it was possible to obtain results more representative of the national reality and were then able to establish the so-called minimum criteria within each item studied.

This way, the minimum number of outpatient consultations that a training center in the foot and ankle area should offer to trainees during one year was 3,500 consultations/year, which corresponds to approximately 292 consultations/month. This number was met only by 15 of the 31 evaluated services (48\%). 
Table 3. Hierarchical classification of the 31 services surveyed based on the score obtained

\begin{tabular}{|c|c|c|c|c|}
\hline Classification & Training Center & State & Score & Concepts \\
\hline 1 & HC da Faculdade de Medicina da USP - IOT & SP & 9.5 & Excellent \\
\hline 2 & Universidade Federal de São Paulo - UNIFESP & SP & 9.5 & Excellent \\
\hline 3 & Pavilhão Fernandinho - Santa Casa de São Paulo & SP & 8.0 & Good + \\
\hline 4 & Hospital Madre Teresa - Belo Horizonte & MG & 7.0 & Good - \\
\hline 5 & Universidade Federal do Paraná & PR & 6.9 & Good - \\
\hline 6 & Universidade Federal de Goiás & $\mathrm{GO}$ & 6.4 & Good - \\
\hline 7 & Instituto de Ortopedia - INTO & RJ & 5.7 & Sufficient + \\
\hline 8 & Hospital Governador Israel Pinheiro - Belo Horizonte & MG & 5.2 & Sufficient + \\
\hline 9 & Residência Médica COT - Martagão & BA & 5.2 & Sufficient + \\
\hline 10 & Ortopedia e Traumatologia de São José do Rio Preto & SP & 5.0 & Sufficient + \\
\hline 11 & Instituto Ortopédico de Goiânia & GO & 4.9 & Sufficient - \\
\hline 12 & Hospital Mater Dei - Belo Horizonte & MG & 4.9 & Sufficient - \\
\hline 13 & Hospital e Maternidade Celso Pierro - PUC Campinas & SP & 4.5 & Sufficient - \\
\hline 14 & Instituto Ortopedia e Traumatologia & SC & 4.4 & Sufficient - \\
\hline 15 & Hospital do Servidor Público Estadual & SP & 4.2 & Sufficient - \\
\hline 16 & Hospital Dr. Homero Miranda Gomes & SC & 4.2 & Sufficient - \\
\hline 17 & Universidade Estadual de Campinas & SP & 4.2 & Sufficient - \\
\hline 18 & Complexo Hospitalar do Mandaqui & SP & 3.9 & Poor + \\
\hline 19 & Hospital IFOR - São Paulo & SP & 3.9 & Poor + \\
\hline 20 & Hospital de Ortopedia e Traumatologia da FMABC & SP & 3.6 & Poor + \\
\hline 21 & Universidade Federal de Uberlândia - HC Ortopédico & MG & 3.4 & Poor + \\
\hline 22 & Hospital Nossa Senhora do Pari & SP & 3.4 & Poor + \\
\hline 23 & Hospital Universitário de Taubaté & SP & 3.0 & Poor + \\
\hline 24 & Instituto de Ortopedia de Passo Fundo & RS & 3.0 & Poor + \\
\hline 25 & RIBOT - Hospital Santa Izabel & BA & 2.9 & Poor - \\
\hline 26 & Hospital Santa Marcelina & SP & 2.9 & Poor - \\
\hline 27 & Hospital Cajuru - Curitiba & PR & 2.9 & Poor - \\
\hline 28 & Hospital Clementino Fraga & RJ & 2.9 & Poor - \\
\hline 29 & Hospital Municipal Lourenço Jorge & RJ & 1.9 & Insufficient + \\
\hline 30 & Hospital Evangélico - Curitiba & $\mathrm{PR}$ & 1.5 & Insufficient + \\
\hline 31 & Santa Casa da Misericórdia do Rio de Janeiro & RJ & 0.5 & Insufficient - \\
\hline
\end{tabular}

The minimum number of surgeries performed during one year was stipulated as 315 surgeries/year, which corresponds to approximately 26 surgeries/month. This number was met by 19 of the 31 evaluated services (61\%). Using the corrected mean proportion, we established $9 \%$ as the ideal ratio between the number of outpatient visits and the number of surgeries performed over the course of a year.

In our evaluation, we prioritized the performance of 20 essential types of surgical treatment modalities considering the importance and the need for the trainee to learn how to treat the most prevalent diseases in the foot and ankle daily clinical practice. Thus, we established the criteria for an official reference base for performing the essential types of surgical treatment modalities (see Table 1).
With some concern, we observed that only six of the 19 services that managed to meet the target of 315 surgeries/year were able to offer the physician in training the possibility of experiencing the treatment of at least 15 of the 20 essential types of surgical treatment modalities deemed essential according to the study. We identified that some of the surgical treatments considered essential were not performed in a few training centers: the treatment of congenital clubfoot in the newborn was not performed in 13 services (42\%); no treatment using a circular external fixator was performed in three services (10\%); while major amputation was not performed in three services (10\%). The data above make us reflect on the necessity of offering the physicians in training more options, so that they can fully develop their essential technical skills. 
Besides the variety of surgeries offered in the training program, we also analyzed the size of interventions performed by the training centers. Based on the study performed, we established the following as reference values according to the corrected annual mean distribution of the surgeries complexity: size I - major, high complexity surgeries: $15 \%$ of the total surgeries performed; size II - medium, moderate complexity surgeries: $66 \%$ of surgeries performed; and size III - minor, low complexity surgeries: $19 \%$ of surgeries performed. We found that only eight (26\%) of the 31 training centers met the target of performing at least $15 \%$ of high complexity surgeries. It warns us that the training offered in most centers might be not providing the necessary experience in relation to the surgical treatment of more severe and complex cases.

The scoring scale created and used in this study scored the training centers capable of meeting the minimum annual number of outpatient consultations $(3,300)$ and surgeries (315) four points. Another criterion adopted was the size of the surgeries performed, worth one point. Taking these criteria into account, it would be possible to score five as long as the minimum number of consultations and surgeries was met.

The remaining five points of the assessment scale concerned academic criteria, such as the clinical staff qualification; scientific production criteria, represented by publications in national and international journals; the theoretical teaching program; and the structural organization of the service.

Also regarding the academic criteria, the clinical staff qualification was considered important for allowing the instructor to properly execute the necessary theoretical teaching program. We believe that a properly qualified instructor has the necessary didactic preparation to perform his teaching functions, and it is strongly recommendable for any advanced training center to be backed by the criteria adopted by the Ministry of Education and Culture, having its clinical staff formed by masters and PhDs. However, it was quite worrying to identify that eight (26\%) of the 31 accredited services do not have any member with academic degrees among their instructors. Twenty-three services had instructors holding academic degrees: seven services had at least one master, while 16 had at least one $\mathrm{PhD}$ in their clinical staff.

The quantity and quality of the national scientific production of the 31 accredited foot and ankle training centers showed that we are still very far from the level of excellence in this criterion. In the period studied, three services (10\%) did not make any publication. Among the 220 articles pu- blished by the remaining 28 services, the vast majority (159 articles $-72 \%$ ) were published in national journals. Only 16 of the 61 articles published in international journals were classified as A level publications, corresponding to $26 \%$ of all international publications. The remaining 45 international publications were in $B$ level journals according to the criteria adopted in this study. On the other hand, four training centers alone were responsible for all $A$ level international publications, corresponding to only $13 \%$ of the total services.

The evaluation of the theoretical program, consisting of classes, seminars, discussion of clinical cases, and participation in scientific meetings offered to physicians in training, and the data related to the organization of the training center provided indicators of the efficiency and comprehensiveness of the training centers regarding the qualification required to address the program and to offer a basic training of quality. Based on this study, we developed a minimum theoretical program specifying the essential topics that must necessarily be addressed. We further established the need to hold a defined number of clinical meetings to discuss topics relevant to the treatment of foot and ankle disorders within the theoretical program.

The organization of documentation and statistical data regarding the training program, the number of elective outpatient consultations, and surgical treatments was assessed subjectively using direct data and considering possible contradictions in the information provided. Unfortunately, we still found that at least ten services were excessively disorganized and had poorly documented information. In some cases, the information obtained from the study protocol sent by email indicated that the inadequate filling was, quite possibly, due to the relative conflict of the reported data, characterized by discrepant or incorrect numbers. For these ten services classified as disorganized, it was necessary to check and correct some previously informed data several times, and this was only possible after successive contacts with the head of the training center.

To conclude, this study showed that even adopting not very demanding criteria for assessing the quality of the training offered by the 31 accredited services, only two (7\%) of them were classified as centers of excellence, four (13\%) performed well, while other 11 (35\%) were classified as having sufficient quality. Besides, other 11 (35\%) of them were considered of low and questionable quality, and it is recommended that they improve their performance urgently. Three services (10\%) showed insufficient performance and the possibility of de-accreditation should be seriously considered. 
It is important to stress that this study was a pioneer in this area of approach within the specialized training targeted at foot and ankle orthopedic surgery. The fact that there is no precedent in the national literature makes it an important reference to establish minimum criteria in order to guide the qualification of centers that intend to offer specialized training for foot and ankle surgeons. The basic, essential conditions of the education and training program have also been established and constitute a reference source for those responsible for accrediting applicants who wish to operate, in the future, as training centers for foot and ankle surgeons.

\section{CONCLUSION}

This study allowed the creation of a reference base capable of directing, through objective quality criteria, the basic conditions required from training centers to improve and standardize the qualification of orthopedists in training in the foot and ankle area in the national territory.

Author's contribution: Each author personally and significantly contributed towards the development of this article: RCF *(https://orcid.org/0000-00029886-5082) conceived and planned the activities that led to the study, wrote the article, interpreted the results of the study, participated in the review process, data collection, bibliographic review, approved the final version; MTC *(https://orcid.org/0000-0001-9411-9376) wrote the article, interpreted the results of the study, participated in the review process, data collection, bibliographic review, approved the final version. ${ }^{*}$ ORCID (Open Researcher and Contributor ID).

\section{REFERENCES}

1. Ferreira RC. Development of a minimum theoretical-practical training program to graduate Brazilian physicians in foot and ankle surgery. Rev ABTPé. 2013;7(2):68-78.

\section{PHYSICIAN RESPONSABLE AT THE TRAINING CENTERS ACCREDITED WITHIN THE BRAZILIAN SOCIETY OF MEDICINE AND SURGERY OF THE ANKLE AND FOOT}

Assaumi ID: Physician responsible for the training center in foot and ankle surgery at Hospital IFOR - São Bernardo do Campo - SP

Barroco RS: Physician responsible for the training center in foot and ankle surgery at Faculdade de Medicina do ABC - Santo André - SP

Batista AD: Physician responsible for the training center in foot and ankle surgery at Associação Beneficente de Assistência Social Nossa Senhora do Pari - São Paulo - SP

Benevides WA: Physician responsible for the training center in foot and ankle surgery at Hospital Madre Teresa - Belo Horizonte - MG

Bittar CK: Physician responsible for the training center in foot and ankle surgery at Hospital e Maternidade Celso Pierro da PUC Campinas - SP

Castro Jr IM: Physician responsible for the training center in foot and ankle surgery at the Instituto Nacional de Traumatologia e Ortopedia - Rio de Janeiro - RJ

Cohen JC: Physician responsible for the training center in foot and ankle surgery at Hospital Clementino Fraga - Rio de Janeiro - RJ

Dinato MCM: Physician responsible for the training center in foot and ankle surgery at Universidade Estadual de Campinas - SP

Demore AB: Physician responsible for the training center in foot and ankle surgery at Instituto de Ortopedia e Traumatologia de Santa Catarina - Joinville - SC
Ferreira RC: Physician responsible for the training center in foot and ankle surgery at Departamento de Ortopedia e Traumatologia da Santa Casa - São Paulo - SP

Ferro GM: Physician responsible for the training center in foot and ankle surgery at Instituto Ortopédico de Goiânia - GO

Figueiredo MG: Physician responsible for the training center in foot and ankle surgery at Hospital de Base - São José do Rio Preto - SP

Godoy-Santos, AL: Physician responsible for the training center in foot and ankle surgery at Instituto de Ortopedia e Traumatologia da USP - São Paulo - SP

Jambeiro JES: Physician responsible for the training center in foot and ankle surgery at Hospital Santa Izabel - Salvador - BA

Lara LCR: Physician responsible for the training center in foot and ankle surgery at Hospital Universitário de Taubaté - SP

Lima E: Physician responsible for the training center in foot and ankle surgery at Instituto de Ortopedia de Passo Fundo - RS

Maluf Neto J: Physician responsible for the training center in foot and ankle surgery at Complexo Hospitalar do Mandaqui - São Paulo - SP

Martins JS: Physician responsible for the training center in foot and ankle surgery at Faculdade de Medicina da Universidade Federal de Goiás - Goiânia - GO

Martynetz JR: Physician responsible for the training center in foot and ankle surgery at Hospital Cajurú - Curitiba - PR

Mezêncio AC: Physician responsible for the training center in foot and ankle surgery at Hospital Israel Pinheiro - Belo Horizonte - MG

Molina WF: Physician responsible for the training center in foot and ankle surgery at Hospital do Servidor Público Estadual - São Paulo - SP Moreno MVMG: Physician responsible for the training center in foot and ankle surgery at Hospital Martagão - Salvador - BA

Moura CR: Physician responsible for the training center in foot and ankle surgery at Santa Casa de Misericórdia do Rio de Janeiro - RJ 
Nacime M: Physician responsible for the training center in foot and ankle surgery at Universidade Federal de São Paulo - SP

Ostrowski MAR: Physician responsible for the training center in foot and ankle surgery at Hospital Regional Homero de Miranda Gomes - São José - SC

Padula EOC: Physician responsible for the training center in foot and ankle surgery at Hospital Municipal Lourenço Jorge - Rio de Janeiro - RJ Pereira CAB: Physician responsible for the training center in foot and ankle surgery at Hospital Municipal Evangélico - Curitiba - PR

Pereira CJ: Physician responsible for the training center in foot and ankle surgery at Hospital das Clínicas Ortopedia da Universidade Federal de Uberlândia - MG

Prata SDS: Physician responsible for the training center in foot and ankle surgery at Hospital Santa Marcelina - São Paulo - SP

Silva JLV: Physician responsible for the training center in foot and ankle surgery at Hospital de Clínicas da Universidade Federal do Paraná - Curitiba - PR
Benevides WA: Physician responsible for the training center in foot and ankle surgery at Hospital Madre Teresa - Belo Horizonte - MG

Zambelli R: Physician responsible for the training center in foot and ankle surgery at Hospital Mater Dei - Belo Horizonte - MG

\section{ABOUT THE AUTHORS}

Ricardo Cardenuto Ferreira

ABTPés Education and Training Director - period 2008-2009 and 2012-2015

Continuing Education and Research Director - period 2010-2011

\section{Marco Túlio Costa}

President of ABTPé - period 2018-2019

Vice President of ABTPé - period 2016-2017

ABTPé Secretary - period 2010-2015

ABTPé Treasurer - period 2008-2009 